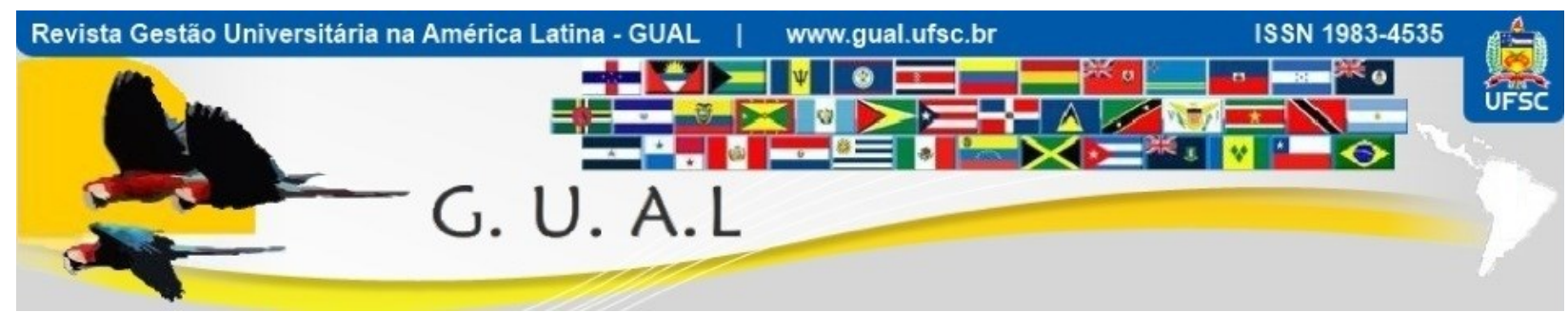

DOI: http://dx.doi.org/10.5007/1983-4535.2019v12n2p72

\title{
O ESTUDO DA DISCIPLINA DE EMPREENDEDORISMO NAS INSTITUIÇÕES DE ENSINO SUPERIOR DE ADMINISTRAÇÃO DE ARACAJU E DE SÃO CRISTÓVÃO (SE)
}

\author{
STUDY OF THE ENTREPRENEURSHIP DISCIPLINE IN THE HIGHER \\ EDUCATION INSTITUTIONS OF ARACAJU AND SÃO CRISTÓVÃO (SE)
}

\author{
Naiane Karoline Santos Correia, Graduada \\ https://orcid.org/0000-0003-0945-989X \\ naiane_karoline@hotmail.com \\ Universidade Federal de Sergipe | Departamento de Administração \\ Aracaju | Sergipe | Brasil \\ Iracema Machado de Aragão, Doutora \\ https://orcid.org/0000-0002-4328-191X \\ aragao.ufs@gmail.com \\ Universidade Federal de Sergipe | Departamento de Administração \\ Aracaju | Sergipe | Brasil \\ Amanda Luiza Soares Silva, Mestre \\ http://orcid.org/0000-0003-3085-5870 \\ amandalsoaressilva@gmail.com \\ Universidade Federal de Sergipe | Departamento de Administração \\ Aracaju | Sergipe | Brasil
}

Recebido em 09/junho/2018

Aprovado em 07/fevereiro/2019

Publicado em 02/maio/2019

Sistema de Avaliação: Double Blind Review

Esta obra está sob uma Licença Creative Commons Atribuição-Uso. 


\title{
RESUMO
}

A educação empreendedora é importante para a formação profissional dos empreendedores ou aqueles que trabalharão em empresas, na criação de negócios competitivos, na empregabilidade e para o desenvolvimento econômico do país. O objetivo do estudo foi analisar a influência das práticas didático-pedagógicas no estudo da disciplina de Empreendedorismo, adotadas pelas Instituições de Ensino Superior - IES do curso de Administração de Aracaju e de São Cristóvão/SE. A metodologia utilizada é o estudo de casos múltiplos e o roteiro de entrevista semi-estruturado teve como base a Matriz de Estilos de Aprendizagem e Técnicas Pedagógicas de Ulrich e Cole (1987). Esse estudo teve como resultados que as disciplinas de empreendedorismo são ofertadas a partir do $5^{\circ}$ período na maioria das IES participantes e todas as IES utilizam as práticas didático-pedagógicas, tais como, filmes, palestras e aulas expositivas, diálogos, discussões limitadas, estudos de casos, avaliação de problemas e instrução programa.

Palavras-chave: Educação Empreendedora. Ensino de Empreendedorismo. Práticas DidáticoPedagógicas.

\begin{abstract}
Entrepreneurship education is important for the professional training of entrepreneurs or those who will work in companies, in creating competitive businesses, in employability and for the economic development of the country. The objective of the study was to analyze the influence of didactic-pedagogical practices in the study of the discipline of Entrepreneurship, adopted by the Institutions of Higher Education - IES of the Administration course of Aracaju and São Cristóvão/SE. The methodology used is the study of multiple cases and the semi-structured interview script was based on the Matrix of Learning Styles and Pedagogical Techniques of Ulrich and Cole (1987). This study had the results that entrepreneurship subjects are offered from the 5th period in most of the participating HEIs and all HEIs use didactic-pedagogical practices, such as films, lectures and expository classes, dialogues, limited discussions, cases, problem assessment and program instruction.
\end{abstract}

Keywords: Entrepreneurship Education. Entrepreneurship Teaching. Didactic-Pedagogical Practices. 


\section{INTRODUÇÃO}

O Empreendedorismo é indispensável para o desenvolvimento socioeconômico de qualquer país e o seu estudo facilita o aprimoramento da capacidade criativa, persistente e de inovação, além de contribuir na implementação de ideias, na antecipação aos fatos, na busca por oportunidades e na responsabilidade de riscos.

Após várias tentativas de estabilização da economia e da imposição advinda do fenômeno da globalização, empresas brasileiras de grande porte tiveram de procurar alternativas para aumentar a competitividade, reduzir os custos e manter-se no mercado; uma das consequências imediatas foi o aumento do índice de desemprego, que desencadeou a criação de novos negócios (DORNELAS, 2008).

Os Estudos do Instituto Brasileiro da Qualidade e Produtividade (IBQP) (2013) têm como foco principal o indivíduo empreendedor, mais do que o empreendimento em si e avalia o Empreendedorismo segundo as etapas do processo empreendedor, que vão desde o momento em que os indivíduos expressam a intenção de iniciar um empreendimento, até a criação e a manutenção do negócio em suas fases iniciais ou quando este já é considerado estabelecido.

Entende-se como Empreendedorismo "qualquer tentativa de criação de um novo empreendimento, como por exemplo: uma atividade autônoma, uma nova empresa ou a expansão de um empreendimento existente" (IBQP, 2012, p. 19).

É importante ressaltar o papel do empreendedor enquanto líder e responsável pela criação, gestão e manutenção de negócios. Segundo Dornelas (2008), um profissional com este perfil faz a diferença nas organizações por ser considerado visionário, otimista e apaixonado pelo que faz. Trata-se de uma pessoa com competências diferenciadas, capaz de criar valor para a sociedade na qual se encontra inserido, buscando soluções para melhorar a vida das pessoas.

A educação dos brasileiros por meio da preparação para a prática empreendedora é importante, pois, possibilita a melhora no rendimento de oportunidades e aumenta o efeito de empregabilidade, que é demonstrado através do percentual de participação das pequenas empresas no Produto Interno Bruto - PIB nacional (YSHIKAWA SALUSSE; ANDREASSI, 2016).

O objetivo geral deste trabalho é analisar a influência das práticas didáticopedagógicas no estudo da disciplina de Empreendedorismo, adotadas pelas Instituições de 
Ensino Superior - IES do curso de Administração de Aracaju e de São Cristóvão/SE, seguindo o modelo de Ulrich e Cole (1987) e na ótica dos docentes.

\section{EMPREENDEDORISMO}

Para Amarós, Fernández e Tapia (2012), o Empreendedorismo é uma atividade bastante importante para a competitividade e crescimento dos países, principalmente no que se refere à possibilidade de mobilidade social, a partir da criação de novos empregos, sendo evidente que diferentes países ou regiões apresentam diferentes dinâmicas entre o grau de Empreendedorismo e seus estágios de competitividade.

Diferenças entre correntes que abordam o Empreendedorismo são provocadas por percepções e definições que partem de diferentes premissas, no entanto, Filion (1999) afirma que o pensamento científico sobre o tema é dividido em duas correntes principais, a corrente dos economistas e a corrente dos comportamentalistas.

Pode-se perceber que o Empreendedorismo é um tema que tem despertado muito interesse no meio acadêmico e fora dele, dado sua importância socioeconômica, e o fato de que a produção de conhecimento científico a partir dele é crescente.

\subsection{CONCEITO E ORIGEM DO EMPREENDEDORISMO}

Os primeiros a estudarem o universo dos empreendedores foram os economistas Richard Cantillon (1680-1734), Jean-Baptiste Say (1767-1832) e Joseph Alois Schumpeter (1883-1950). Esta corrente, conhecida como a dos economistas, relaciona o empreendedor a aspectos relativos à identificação de oportunidades de negócio e à geração de lucro que leve às mudanças desejadas (FILION, 1999).

O economista francês Jean-Baptiste Say, tido como pai do Empreendedorismo, considerava, por volta de 1800, o empreendedor aquele que transferia recursos de um setor com baixa produtividade para outro de produtividade maior e com rendimento mais elevado e; um ser dotado de características ligadas à inovação (DRUCKER, 1987).

Schumpeter (1982) foi o primeiro teórico a observar e destacar a importância do empreendedor na economia, afirmando ser este o "motor da economia capitalista". O economista acredita que Empreendedorismo e inovação atuam em simbiose.

Segundo ele, o empreendedor promove a "destruição criativa", um processo que introduz o novo e gera desenvolvimento e riqueza para uma nação, sendo um impulso 
fundamental que aciona e mantêm em marcha o motor da economia capitalista, criando novos produtos, novos modos de produção, novos mercados.

Na visão de Filion (1999), essa corrente está relacionada aos psicólogos, psicanalistas, sociólogos e outros especialistas do comportamento humano, citando Max Weber como um dos seus pioneiros. Para Martinelli e Fleming (2010), os estudiosos desta corrente olham o empreendedor à luz do conjunto de valores próprios e específicos que conduzem sua ação de empreender.

\subsection{PERFIL DO EMPREENDEDOR}

Schumpeter (1934) define empreendedor como aquele ser que é capaz de aproveitar as chances das mudanças tecnológicas e introduzir processos inovadores nos mercados. A função do empreendedor é reformar ou revolucionar os padrões de produção, explorando uma tecnologia não experimentada para produzir um novo produto ou um antigo produto de uma nova forma, de modo a proporcionar uma nova fonte de suprimento de materiais ou uma nova forma de comercialização de produtos, organizando um novo setor (SCHUMPETER, 1950).

Nessa situação, os empreendimentos são, em sua maioria, informais, focados no momento atual, sem utilização de instrumentos de planejamento, sem visão de futuro, sem identificação de oportunidades e de nichos de mercado e descomprometidos com o crescimento e desenvolvimento econômico do país.

Segundo Hisrich, Peters e Shepherd (2014), o empreendedor segue o que acredita ser uma oportunidade. Como as oportunidades existem em (ou criam e/ou geram) um estado de forte incerteza, os empreendedores precisam utilizar seu discernimento para decidir se devem ou não agir. Mas a dúvida também pode minar a ação empreendedora.

\subsection{ENSINO DO EMPREENDEDORISMO}

As recentes mudanças no ambiente macroeconômico instauraram uma nova realidade empresarial, pautada pela falta de previsibilidade, pelo acirramento do ambiente competitivo, pela necessidade de tomada de decisões rápidas e pelo aumento exponencial da incerteza (MASSAINI et al., 2012).

Segundo Boaventura e Lopes Melo (2012), o número de jovens empreendedores vem aumentando no Brasil, pela dificuldade em conseguir trabalho ou pelo desejo de ter o próprio 
negócio e não ter patrão. Por necessidade ou por vontade de ter o próprio negócio, os jovens se aventuram cada vez mais na criação de novos negócios.

A importância do jovem na economia tem se tornado cada vez mais relevante por apresentar características peculiares: cada vez mais cedo tem acesso à informação, grande domínio do conhecimento, é fanático por novidades e tem alto poder de influência sobre as decisões das outras gerações, além de que os jovens entram para a faculdade já pensando em montar o próprio negócio, sem imaginar as dificuldades que irão encontrar nesse processo (SOARES; MACHADO, 2005; BOAVENTURA; LOPES MELO, 2012).

De acordo com Hisrich, Peters e Shepherd (2014), ainda que uma educação formal não seja necessária para iniciar um negócio, como se constata pelo sucesso de pessoas como Andrew Carnegie, William Durant, Henry Ford e William Lear, que não concluíram a escola secundária, ela realmente oferece uma boa experiência, em especial quando tem a ver com a área de empreendimento.

Para acompanhar o desenvolvimento do Empreendedorismo no Brasil e no mundo, o Global Entrepreneurship Monitor (GEM) realizou uma pesquisa internacional liderada pela London Business School e o Babson College (EUA) cuja proposta foi avaliar o Empreendedorismo no mundo a partir de indicadores comparáveis (IBQP, 2012).

Desde 1999, quando realizou seu primeiro ciclo, até hoje, o estudo envolveu mais de 40 países de todos os continentes e dos mais variados graus de desenvolvimento econômico e social, tornando-se a investigação de maior escopo em sua área.

\subsubsection{Práticas didático-pedagógicas adotadas no ensino do Empreendedorismo pelas Instituições de Ensino Superior / Programas e planos de ensino no Brasil}

Segundo Araújo et al. (2012), a preocupação não deve somente provir das organizações, mas também das instituições de ensino que oferecem as competências que os estudantes necessitam para desenvolver suas habilidades e conseguirem seu espaço nas organizações. O grande percentual de bacharéis que as instituições formam e lançam no mercado tem sido um problema relevante nas IES, pois se observa uma dissonância com os altos índices de desemprego. Esse cenário surge devido ao enxugamento do quadro de funcionários nas grandes organizações, reestruturações, fechamento e fusões, entre outros fatores.

Araújo et al. (2012) afirma que um dos caminhos que poderiam ser, e vem sendo, trilhado na busca da inserção das IES e Universidades seria acrescentar às grades curriculares 
o ensino de Empreendedorismo em conjunto com as práticas didático-pedagógicas adequadas para essa abordagem. Essa mudança nas instituições poderia contribuir para a formação de profissionais graduados mais preparados e habilitados no que se refere à gestão dos negócios e abertura de novos empreendimentos. Para se atingir tal nível, as instituições têm de viabilizar novos meios que despertem a criatividade e a inovação nos estudantes.

\subsubsection{Desafios do ensino do empreendedorismo na graduação em uma IES}

A atividade empreendedora e o processo de criação de empresas aparecem com crescente destaque no debate acadêmico e nas medidas de políticas com vistas ao desenvolvimento industrial e econômico (GARCIA et al., 2012).

A educação é importante na criação do empreendedor, a importância se reflete não só no nível educacional obtido, mas também no fato de que continua a desempenhar um grande papel ao auxiliar a lidar com os problemas que os empreendedores enfrentarão. Os valores pessoais são importantes para os empreendedores. Muitas vezes os estudos não conseguem indicar que os empreendedores podem se diferenciar de gerentes, empreendedores sem sucesso ou mesmo da população em geral, em relação a esses valores (ARAÚJO et al., 2012).

Para Garcia et al. (2012), os empreendedores acadêmicos apresentam uma capacidade superior à média para a criação de novas empresas e, dessa forma, para levar a cabo atividades inovativas e intensivas em conhecimento e sustentadas por mais um amplo grupo de trabalhadores qualificados. Supõe-se assim, que as empresas criadas a partir de uma base mais ampla de conhecimentos são mais capazes de estabelecer essas atividades e exercer efeitos positivos sobre o emprego, o crescimento econômico e a competitividade.

As Instituições de Ensino Superior precisam enfrentar o desafio de aproximar, o máximo possível, o aluno do mundo exterior à sala de aula, considerando que o principal aprendizado está na capacidade de sondar o mercado e enxergar oportunidades (VIEIRA et al., 2013).

\section{METODOLOGIA}

A pesquisa em questão é caracterizada como de natureza descritiva com abordagem qualitativa ou exploratória-interpretativa (GIL, 2010), visto que serão analisados os programas de curso das disciplinas relacionados ao Empreendedorismo, e realizadas entrevistas para a coleta de evidências. 


\section{O ESTUDO DA DISCIPLINA DE EMPREENDEDORISMO NAS INSTITUIÇÕES DE ENSINO SUPERIOR DE ADMINISTRAÇÃO DE ARACAJU E DE SÃO CRISTÓVÃO (SE) \\ DOI: http://dx.doi.org/10.5007/1983-4535.2019v12n2p72}

O método de pesquisa utilizado é o estudo de casos múltiplos (YIN, 2010), pois tem o intuito de compreender e descrever a forma de ensino do Empreendedorismo pelas IES em Aracaju em São Cristóvão e, o desenvolvimento das características do perfil empreendedor no aluno do curso de Administração.

O roteiro de entrevista semi-estruturado teve como base a Matriz de Estilos de Aprendizagem e Técnicas Pedagógicas de Ulrich e Cole (1987), apresentada no Quadro 01.

Quadro 01 Estilos de Aprendizagem e Técnicas Pedagógicas

\begin{tabular}{|c|c|}
\hline \multicolumn{2}{|c|}{ MATRIZ DE ESTILOS DE APRENDIZAGEM E TÉCNICAS PEDAGÓGICAS } \\
\hline Experimentação ativa & Observação reflexiva \\
\hline $\begin{array}{c}\text { Quadrante III } \\
\text { Ativo-aplicado } \\
\text { (mudanças em habilidades e atitudes) }\end{array}$ & $\begin{array}{c}\text { Quadrante II } \\
\text { Reflexivo-aplicado } \\
\text { (mudança na avaliação) }\end{array}$ \\
\hline $\begin{array}{l}\text { Jogos em papéis (ou de negócios) } \\
\text { Simulações de gerenciamento } \\
\text { Exercícios estruturados } \\
\text { Processos de discussões } \\
\text { Grupo T } \\
\text { Diários } \\
\text { Visitas técnicas ao Pólo } \\
\text { Projetos de campo (plano de negócios) } \\
\end{array}$ & $\begin{array}{c}\text { Filmes } \\
\text { Palestras e aulas expositivas } \\
\text { Diálogos } \\
\text { Discussões limitadas } \\
\text { Estudos de caso } \\
\text { Avaliação de problemas } \\
\text { Instrução programada* }\end{array}$ \\
\hline $\begin{array}{c}\text { Quadrante IV } \\
\text { Ativo-teórico } \\
\text { (mudanças na compreensão, entendimento) }\end{array}$ & $\begin{array}{c}\text { Quadrante I } \\
\text { Reflexivo-teórico } \\
\text { (mudança no conhecimento) }\end{array}$ \\
\hline $\begin{array}{l}\text { Trabalhos de grupo } \\
\text { Discussões argumentadas } \\
\text { Experimentos/pesquisa } \\
\text { Sugestões de leitura } \\
\text { Análise de artigos }\end{array}$ & $\begin{array}{c}\text { Aulas e palestras teóricas } \\
\text { Leituras obrigatórias } \\
\text { Anotações do professor } \\
\text { Instrução programada* (conceitos) } \\
\text { Artigos teóricos } \\
\text { Avaliação de conteúdo }\end{array}$ \\
\hline $\begin{array}{l}\text { (*) Instrução programada é a mais conl } \\
\text { desenvolvidos pelo psicólogo estadunidense } S \\
\text { ser ensinado em módulos, ou seja, peque } \\
\text { instrução programada o aprendiz recebe un } \\
\text { sobre ela e, também imediatamente, rec } \\
\text { memorização de conceitos. }\end{array}$ & $\begin{array}{l}\text { aplicação educacional dos conceitos } \\
\text { (1904). Consiste em dividir o material a } \\
\text { egmentos logicamente encadeados. Na } \\
\text { strução, é logo em seguida questionado } \\
\text { o retorno. Visa fundamentalmente à } \\
\end{array}$ \\
\hline
\end{tabular}

Fonte: Adaptado de Ulrich e Cole (1987).

Para Ulrich e Cole (1987), as abordagens pedagógicas direcionadas ao ensino do Empreendedorismo estão dispostas nos quadrantes III e IV, pois exigem que o docente tome um comportamento secundário, assumindo a disciplina somente como orientador e observador do processo de aprendizagem.

A amostra da pesquisa foi composta por docentes das IES de Aracaju e de São Cristóvão, selecionadas por ofertarem a disciplina de Empreendedorismo na matriz curricular 


\section{O ESTUDO DA DISCIPLINA DE EMPREENDEDORISMO NAS INSTITUIÇÕES DE ENSINO SUPERIOR \\ DE ADMINISTRAÇÃO DE ARACAJU E DE SÃO CRISTÓVÃO (SE) \\ DOI: http://dx.doi.org/10.5007/1983-4535.2019v12n2p72}

do curso de Administração. Os roteiros de entrevista semi-estruturados foram respondidos por 9 (nove) professores, sendo 8 (oito) de instituições particulares e 1 (um) de universidade pública federal, no período entre dezembro de 2015 e abril de 2016.

E, a etapa seguinte constitui-se da transcrição das entrevistas, as quais passaram por uma análise de conteúdo, a qual, segundo Bardin (2011), consiste em um conjunto de técnicas de análise de comunicações, que propicia a compreensão de aspectos capazes de ampliar o entendimento. E essa análise é constituída das seguintes fases: 1) a análise prévia, seleção do material e determinação dos procedimentos a serem seguidos; 2) a exploração do material, implementação destes procedimentos e 3) o tratamento e a interpretação dos resultados.

O quadro 02 abaixo apresenta as categorias analíticas desta pesquisa foram formuladas de acordo com a revisão teórica.

Quadro 02 Categorias analíticas e elementos de análise

\begin{tabular}{|l|l|}
\hline \multicolumn{1}{|c|}{ Categorias analíticas } & \multicolumn{1}{c|}{ Elementos de análise } \\
\hline $\begin{array}{l}\text { Características das Instituições } \\
\text { de Ensino Superior - IES } \\
\text { participantes e do curso de } \\
\text { Administração }\end{array}$ & $\begin{array}{l}\text { IES; Ano de fundação; Localização; Ano de formalização do } \\
\text { curso de Administração/ Funcionamento; Quantidade total de } \\
\text { disciplinas; Carga horária total do curso; Duração do curso. }\end{array}$ \\
\hline $\begin{array}{l}\text { Perfil dos professores de } \\
\text { Empreendedorismo }\end{array}$ & $\begin{array}{l}\text { Nível de escolaridade; Função; Área de atuação; Tempo de } \\
\text { serviço na IES. }\end{array}$ \\
\hline $\begin{array}{l}\text { Práticas didático-pedagógicas } \\
\text { adotadas }\end{array}$ & $\begin{array}{l}\text { Aulas teóricas; Palestras teóricas; Leituras obrigatórias; Instrução } \\
\text { programada; Artigos teóricos; Avaliação de conteúdo; Filmes; } \\
\text { Palestras e aulas expositivas; Diálogos; Discussões; Estudos de } \\
\text { caso; Avaliação de problemas; Jogos; Simulações de } \\
\text { gerenciamento; Exercícios estruturados; Visitas técnicas ao Pólo; } \\
\text { Plano de Negócios; Trabalhos de grupo; Experimentos/pesquisa; } \\
\text { Sugestões de leitura; Análise de artigos. }\end{array}$ \\
\hline $\begin{array}{l}\text { Desenvolvimento do perfil } \\
\text { empreendedor }\end{array}$ & $\begin{array}{l}\text { Conhece as mudanças tecnológicas; Conhece os processos de } \\
\text { inovação; Identifica/avalia as oportunidades; Desenvolve plano de } \\
\text { negócios; Identifica recursos necessários; Entende sobre gestão; } \\
\text { Desenvolve visão; Persuade terceiros; Desenvolve energia: } \\
\text { motivação, perseverança; Aceita riscos. }\end{array}$ \\
\hline
\end{tabular}

Fonte: Autoras (2016).

\section{ANÁLISE DOS RESULTADOS}

\subsection{APRESENTAÇÃO DAS INSTITUIÇÕES DE ENSINO SUPERIOR}

No Quadro 03 são destacadas as principais características relacionadas às IES participantes da pesquisa. 


\section{O ESTUDO DA DISCIPLINA DE EMPREENDEDORISMO NAS INSTITUIÇÕES DE ENSINO SUPERIOR DE ADMINISTRAÇÃO DE ARACAJU E DE SÃO CRISTÓVÃO (SE) \\ DOI: http://dx.doi.org/10.5007/1983-4535.2019v12n2p72}

Quadro 03 Características das IES participantes e do curso de Administração

\begin{tabular}{|c|c|c|c|c|c|c|}
\hline IES & $\begin{array}{c}\text { Ano de } \\
\text { fundação }\end{array}$ & Localização & $\begin{array}{l}\text { Ano de formalização } \\
\text { do curso de } \\
\text { Administração/ } \\
\text { Funcionamento }\end{array}$ & $\begin{array}{c}\text { Quantidade } \\
\text { total de } \\
\text { disciplinas }\end{array}$ & $\begin{array}{c}\text { Carga } \\
\text { horária } \\
\text { total do } \\
\text { curso }\end{array}$ & $\begin{array}{l}\text { Duração } \\
\text { do curso }\end{array}$ \\
\hline 'A' - UFS & 1963 & $\begin{array}{l}\text { Município de São } \\
\text { Cristóvão }\end{array}$ & 1970 & 44 & $3000 \mathrm{~h}$ & 5 anos \\
\hline 'B' & 2003 & Bairro Centro & $\begin{array}{l}\text { Julho de 2003/ } \\
\text { Janeiro de } 2004\end{array}$ & 40 & $3600 \mathrm{~h}$ & 4 anos \\
\hline ' $\mathrm{C}$ ' & 1997 & Bairro Industrial & $\begin{array}{l}\text { Dezembro de 1997/ } \\
\text { Julho de } 1998\end{array}$ & 38 & $3190 \mathrm{~h}$ & 4 anos \\
\hline 'D' & 1970 & $\begin{array}{c}\text { Bairro } \\
\text { Salgado Filho }\end{array}$ & 1988 & 49 & $2937 \mathrm{~h}$ & 4 anos \\
\hline ' $\mathbf{E}$ ' & 1993 & $\begin{array}{c}\text { Bairro Siqueira } \\
\text { Campos }\end{array}$ & 2003 & 46 & $2880 \mathrm{~h}$ & 4 anos \\
\hline ' $\mathbf{F}$ ' & 1998 & $\begin{array}{c}\text { Bairro } \\
\text { Getúlio Vargas }\end{array}$ & 1998 & 40 & $3360 \mathrm{~h}$ & 4 anos \\
\hline 'G' & 2004 & Bairro Grageru & 2004 & 49 & $3600 \mathrm{~h}$ & 4 anos \\
\hline 'H' & 2009 & Bairro Capucho & 2009 & 44 & $3300 \mathrm{~h}$ & 4 anos \\
\hline ' $I$ ' & 1972 & Bairro Farolândia & 1972 & 42 & $3440 \mathrm{~h}$ & 4 anos \\
\hline
\end{tabular}

Fonte: Dados da pesquisa (2016).

No Quadro 04 são apresentadas, as Instituições de Ensino Superior participantes desta pesquisa, em forma de resumo comparativo, a nomenclatura definida, a ementa, o período e a carga horária de cada uma das disciplinas de Empreendedorismo.

Quadro 04 Resumo comparativo entre as nomenclaturas e as ementas da disciplina de Empreendedorismo das IES

\begin{tabular}{|c|c|c|}
\hline $\begin{array}{c}\text { Instituição de } \\
\text { Ensino Superior }\end{array}$ & Nomenclatura e ementa da disciplina de Empreendedorismo & $\begin{array}{l}\text { Período de oferta/ } \\
\text { Carga horária }\end{array}$ \\
\hline IES 'A' - UFS & $\begin{array}{l}\text { EMPREENDEDORISMO E GESTÃO DE PEQUENOS } \\
\text { NEGÓCIOS: O Empreendedorismo no Brasil e no mundo; } \\
\text { diferenciação entre ideia e oportunidade; intra-Empreendedorismo } \\
\text { (Intrapreneurship); políticas e programas de apoio às pequenas e } \\
\text { médias empresas; aspectos legais para abertura de micro e } \\
\text { pequenas empresas; planejamento estratégico; etapas e estrutura } \\
\text { da elaboração de um plano de negócios. A questão da propriedade } \\
\text { intelectual. }\end{array}$ & $8 \% 60 h$ \\
\hline IES 'B' & $\begin{array}{l}\text { EMPREENDEDORISMO E INOVAÇÃO: (Não disponibilizou a } \\
\text { ementa) }\end{array}$ & $6 \% / 80 \mathrm{~h}$ \\
\hline IES ' $C$ ' & $\begin{array}{l}\text { EMPREENDEDORISMO (disciplina on line): } \\
\text { Empreendedorismo e espírito empreendedor. Habilidades, atitudes } \\
\text { e características dos empreendedores - fatores psicológicos e } \\
\text { sociológicos. Início e ciclo de vida de uma empresa. } \\
\text { Oportunidades de negócios; identificação, seleção e definição do } \\
\text { negócio. Elementos essenciais para iniciar um novo negócio: o } \\
\text { plano de negócio. }\end{array}$ & $1^{\circ} / 75 \mathrm{~h}$ \\
\hline IES 'D’ & $\begin{array}{l}\text { NOVOS NEGÓCIOS E EMPREENDEDORISMO: Escolha do } \\
\text { negócio, conjuntura econômica, planejamento e estratégia, } \\
\text { organização da empresa, marketing, operações, gestão de pessoas, } \\
\text { contabilidade e finanças para empreendedores, planejamento e } \\
\text { implantação do negócio. }\end{array}$ & $6^{\circ} / 73 \mathrm{~h}$ \\
\hline
\end{tabular}




\section{O ESTUDO DA DISCIPLINA DE EMPREENDEDORISMO NAS INSTITUIÇÕES DE ENSINO SUPERIOR DE ADMINISTRAÇÃO DE ARACAJU E DE SÃO CRISTÓVÃO (SE) \\ DOI: http://dx.doi.org/10.5007/1983-4535.2019v12n2p72}

\begin{tabular}{|c|c|c|}
\hline $\begin{array}{c}\text { Instituição de } \\
\text { Ensino Superior }\end{array}$ & Nomenclatura e ementa da disciplina de Empreendedorismo & $\begin{array}{l}\text { Período de oferta/ } \\
\text { Carga horária } \\
\end{array}$ \\
\hline IES 'E’ & $\begin{array}{l}\text { EMPREENDEDORISMO (disciplina on line): Natureza da } \\
\text { Iniciativa Empresarial. Oportunidades de negócios e os riscos. } \\
\text { Criatividade e Inovação. O espírito empreendedor. Tendências de } \\
\text { mercado e suas oportunidades. Perfil do empreendedor. Criação } \\
\text { de projetos e novos negócios. Como abrir a sua própria empresa e } \\
\text { os mecanismos de apoio. Estrutura do Plano de Negócios. }\end{array}$ & $5 \% 60 \mathrm{~h}$ \\
\hline IES 'F' & $\begin{array}{l}\text { EMPREENDEDORISMO (disciplina on line): Análise histórica } \\
\text { do Empreendedorismo. O processo empreendedor. } \\
\text { Empreendedorismo e empresa. A motivação e o perfil do } \\
\text { empreendedor de sucesso; formação e desenvolvimento de } \\
\text { empreendedores; oportunidade de negócios; criatividade e visão } \\
\text { empreendedora; planejamento, ferramentas de gestão e avaliação } \\
\text { de empreendimentos; a oferta de trabalho e a iniciativa } \\
\text { empreendedora; políticas e estratégias competitivas para os } \\
\text { empreendimentos emergentes. O Empreendedorismo social; a } \\
\text { dinâmica dos negócios; órgãos e instituições de apoio a geração de } \\
\text { empreendimentos inovadores. Estrutura básica do plano de } \\
\text { negócios; elaboração do plano de negócios. }\end{array}$ & $6^{\circ} / 80 \mathrm{~h}$ \\
\hline IES ‘G’ & $\begin{array}{l}\text { EMPREENDEDORISMO E PLANO DE NEGÓCIOS: } \\
\text { Formulação das estratégias para abrir um empreendimento (seu } \\
\text { próprio negócio) a partir da identificação do perfil e das } \\
\text { características próprias do futuro empreendedor. Trata também } \\
\text { das definições de um plano de negócios, sua viabilidade e } \\
\text { finalidade para o futuro empreendedor. }\end{array}$ & $6 \% 60 \mathrm{~h}$ \\
\hline IES 'H’ & $\begin{array}{l}\text { EMPREENDEDORISMO: Tipologia; fundamentos; histórico e } \\
\text { definições. Mitos do Empreendedorismo. O processo } \\
\text { empreendedor. Identificando oportunidades. Tipos de negócios. O } \\
\text { Empreendedorismo no agronegócio. O plano de negócios: } \\
\text { problemas e soluções. O empreendedor: características e perfis. } \\
\text { Fatores de sucesso. A importância do empreendedor na } \\
\text { organização. Processo de tomada de decisões. }\end{array}$ & $7 \% / 60 h$ \\
\hline IES 'I’ & EMPREENDEDORISMO: (Não disponibilizou a ementa) & $7^{\circ} / 40 \mathrm{~h}$ \\
\hline
\end{tabular}

Fonte: Pesquisa de campo (2016).

Quanto às ementas das IES 'B' e 'I', até a conclusão deste trabalho, as faculdades não responderam às solicitações de encaminhamento dos programas da disciplina completos para a conclusão do quadro.

\subsection{PERFIL DOS PROFESSORES DE EMPREENDEDORISMO}

Os dados relacionados ao perfil dos professores da disciplina de Empreendedorismo entrevistados estão reunidos para que possam ser melhor visualizados e entendidos, conforme o Quadro 05. 


\section{O ESTUDO DA DISCIPLINA DE EMPREENDEDORISMO NAS INSTITUIÇÕES DE ENSINO SUPERIOR \\ DE ADMINISTRAÇÃO DE ARACAJU E DE SÃO CRISTÓVÃO (SE) \\ DOI: http://dx.doi.org/10.5007/1983-4535.2019v12n2p72}

Quadro 05 Perfil dos professores de Empreendedorismo entrevistados

\begin{tabular}{|c|c|c|c|c|}
\hline IES & $\begin{array}{c}\text { Nível de } \\
\text { escolaridade }\end{array}$ & Função & Área de atuação & $\begin{array}{c}\text { Tempo de serviço na } \\
\text { IES }\end{array}$ \\
\hline 'A' - UFS & Doutor & $\begin{array}{c}\text { Coordenador de pós- } \\
\text { graduação }\end{array}$ & Empreendedorismo & 9 anos \\
\hline 'B' & Especialista & Professor & Administração & 6 anos \\
\hline 'C' & Mestre & Professor & Empreendedorismo & 13 anos \\
\hline 'D' & Especialista & Professor & Administração & 8 anos \\
\hline 'E' & Mestre & Professor & Propaganda e marketing & $\begin{array}{c}1 \text { ano e } \\
6 \text { meses }\end{array}$ \\
\hline 'F' & Doutorando & $\begin{array}{c}\text { Coordenador do } \\
\text { curso }\end{array}$ & Administração & 3 anos \\
\hline 'G' & Doutorando & $\begin{array}{c}\text { Coordenador do } \\
\text { curso }\end{array}$ & Gestão pública & 1 ano \\
\hline 'H' & Mestrando & Professor & $\begin{array}{c}\text { Administração e } \\
\text { gastronomia }\end{array}$ & 2 anos \\
\hline 'I' & Especialista & $\begin{array}{c}\text { Professor assistente } \\
\text { III }\end{array}$ & $\begin{array}{c}\text { Empreendedorismo } \\
17 \text { anos }\end{array}$ \\
\hline
\end{tabular}

Fonte: Pesquisa de campo (2016)

Ao analisar a categoria nível de escolaridade dos docentes, é possível observar que 3 (três) são especialistas, 3 (três) são mestres ou mestrandos e 3 (três) doutores ou doutorandos.

Com relação à função que desempenham na instituição de ensino que lecionam, além de professores da disciplina de Empreendedorismo, somente 2 (dois) são coordenadores de curso e 1 (um) coordenador de pós-graduação.

No que se refere à área de atuação, nota-se que 4 (quatro) dos entrevistados atuam na área de Administração, 3 (três) em Empreendedorismo e os 2 (dois) professores que atuam em áreas distintas, também lecionam a disciplina de Empreendedorismo.

Quanto ao tempo de serviço na IES, deve-se ressaltar que cada roteiro semiestruturado obteve uma informação diferente a essa questão, já que esse dado é pessoal. Contudo, são 4 (quatro) docentes que possuem menos de 5 (cinco) anos na instituição em que lecionam, 3 (três) professores têm entre 6 (seis) e 10 (dez) anos de serviço, e os demais professores trabalham há mais de 10 (dez) anos nas IES.

\subsection{PRÁTICAS DIDÁTICO-PEDAGÓGICAS ADOTADAS PELAS INSTITUIÇÕES DE ENSINO SUPERIOR}

No quadro 06, observa-se à quantidade de IES que adotaram as técnicas didáticopedagógicas. 


\section{O ESTUDO DA DISCIPLINA DE EMPREENDEDORISMO NAS INSTITUIÇÕES DE ENSINO SUPERIOR \\ DE ADMINISTRAÇÃO DE ARACAJU E DE SÃO CRISTÓVÃO (SE) \\ DOI: http://dx.doi.org/10.5007/1983-4535.2019v12n2p72}

Quadro 06 Quantidade de IES que adotaram as técnicas pedagógicas por quadrante

\begin{tabular}{|c|c|}
\hline$\frac{\text { Quadrante III }}{\text { Ativo-aplicado }}$ & $\frac{\text { Quadrante II }}{\text { Reflexivo-aplicado }}$ \\
\hline $\begin{array}{c}\text { Jogos em papéis (ou de negócios): } 4 \\
\text { Simulações de gerenciamento: } 7 \\
\text { Exercícios estruturados: } 8 \\
\text { Processos de discussões: } 7 \\
\text { Visitas técnicas ao Pólo: } 5 \\
\text { Projetos de campo (plano de negócios): } 9\end{array}$ & $\begin{array}{c}\text { Filmes: } 8 \\
\text { Palestras e aulas expositivas: } 8 \\
\text { Diálogos: } 8 \\
\text { Discussões limitadas: } 8 \\
\text { Estudos de caso: } 9 \\
\text { Avaliação de problemas: } 8 \\
\text { Instrução programada: } 7\end{array}$ \\
\hline$\frac{\text { Quadrante IV }}{\text { Ativo-teórico }}$ & $\begin{array}{c}\text { Quadrante I } \\
\text { Reflexivo-teórico }\end{array}$ \\
\hline $\begin{array}{c}\text { Trabalhos de grupo: } 8 \\
\text { Discussões argumentadas: } 7 \\
\text { Experimentos/pesquisa: } \mathbf{5} \\
\text { Sugestões de leitura: } 7 \\
\text { Análise de artigos: } 7\end{array}$ & $\begin{array}{c}\text { Aulas teóricas: } 9 \\
\text { Palestras teóricas: } 8 \\
\text { Leituras obrigatórias: } 9 \\
\text { Instrução programada (conceitos): } 7 \\
\text { Artigos teóricos: } 9 \\
\text { Avaliação de conteúdo: } 9\end{array}$ \\
\hline
\end{tabular}

Fonte: Autoras (2016) com base em Ulrich e Cole (1987).

No que se refere ao quadrante I, as aulas teóricas, as leituras obrigatórias, os artigos teóricos e a avaliação de conteúdo foram práticas adotadas por todas as 9 (nove) IES como forma de aprendizado nas aulas de Empreendedorismo; 7 (sete) docentes utilizaram a instrução programada relacionadas a conceitos; e, as palestras teóricas foram usadas por 8 (oito) IES como técnica de ensino dentro da Instituição e durante a disciplina, apesar de indicar e propor aos discentes a necessidade de participação nessa atividade.

Em relação ao quadrante II, os estudos de caso foram aplicados em sala de aula por todos os 9 (nove) docentes; os filmes, as palestras expositivas, os diálogos e a avaliação de problemas foram adotadas por 8 (oito) das IES com o objetivo de expandir os assuntos lecionados durante a disciplina; e, 7 (sete) das IES utilizaram a instrução programada, na qual, os aprendizes recebem uma instrução e em seguida são questionados sobre o assunto, visando à memorização dos conceitos.

Quanto ao quadrante III, 9 (nove) docentes adotaram o projeto de campo (plano de negócios) como técnica pedagógica, objetivando a prática dos projetos externos e ampliando a visão do aluno; os exercícios estruturados foram utilizados por 8 (oito) IES; as simulações de gerenciamento e processos de discussões foram adotadas por 7 (sete) IES; e, as visitas técnicas ao Pólo e os jogos em papéis (ou de negócios), respectivamente, foram adotadas por 5 e 4 docentes que afirmaram a falta de tempo para a realização das atividades.

No que diz respeito as técnicas do quadrante $\mathbf{I V}$, os trabalhos de grupo foram a técnica mais utilizada por 8 (oito) docentes; 7 (sete) docentes utilizaram as seguintes técnicas: 


\section{O ESTUDO DA DISCIPLINA DE EMPREENDEDORISMO NAS INSTITUIÇÕES DE ENSINO SUPERIOR \\ DE ADMINISTRAÇÃO DE ARACAJU E DE SÃO CRISTÓVÃO (SE) \\ DOI: http://dx.doi.org/10.5007/1983-4535.2019v12n2p72}

discussões argumentadas, sugestões de leitura e análise de artigos; e, somente 5 (cinco) docentes utilizaram experimentos/pesquisa que são vistos de forma teórica ou por meio de exemplos fictícios.

\subsection{DESENVOLVIMENTO DO PERFIL EMPREENDEDOR}

No quadro 07 é possível visualizar o estilo e técnicas do quadrante I da Matriz de Ulrich e Cole (1987) aplicadas às IES.

Quadro 07 Estilo e Técnicas do quadrante I utilizadas pelas IES no desenvolvimento do perfil empreendedor

\begin{tabular}{|c|c|c|c|c|c|c|}
\hline $\begin{array}{c}\text { Estilo e Técnicas I } \\
\text { reflexivo-teórico } \\
\text { (mudança no conhecimento) }\end{array}$ & 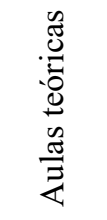 & 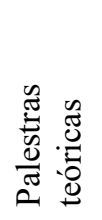 & 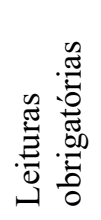 & 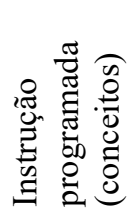 & 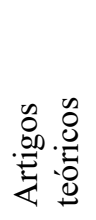 & 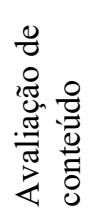 \\
\hline 1. Conhecer mudanças tecnológicas & 7 IES & 5 & 4 & - & 3 & 3 \\
\hline 2. Conhecer processos de inovação & 7 & 3 & 3 & 4 & 3 & 4 \\
\hline 3. Identificar/avaliar oportunidades & 7 & 6 & 2 & 4 & 5 & 5 \\
\hline 4. Desenvolver plano de negócios & 8 & 3 & 6 & 7 & 6 & 7 \\
\hline 5. Identificar recursos necessários & 9 & 5 & 3 & 1 & 2 & 6 \\
\hline 6. Entender sobre gestão & 7 & 5 & 6 & 5 & 4 & 6 \\
\hline 7. Desenvolver visão & 8 & 4 & 5 & 3 & 3 & 5 \\
\hline 8. Persuadir terceiros & 4 & 1 & 2 & 3 & 1 & 4 \\
\hline $\begin{array}{l}\text { 9. Desenvolver energia (motivação, } \\
\text { perseverança) }\end{array}$ & 8 & 5 & 1 & 4 & 3 & 5 \\
\hline 10. Aceitar riscos & 7 & 2 & 2 & 5 & 1 & 4 \\
\hline
\end{tabular}

Fonte: Pesquisa de campo (2016)

Em relação ao quadrante I, as técnicas mais utilizadas pelos professores da disciplina de Empreendedorismo para o desenvolvimento do interesse em conhecer as mudanças tecnológicas são as aulas teóricas adotadas por 7 (sete) Instituições de Ensino Superior, as palestras teóricas em 5 (cinco) e as leituras obrigatórias em 4 (quatro) IES, com esse objetivo.

Para conhecer processos de inovação, persuadir terceiros, desenvolver plano de negócios e tendo em vista à aceitação de riscos, as IES confirmaram adotar, principalmente, as aulas teóricas, a instrução programada e a avaliação de conteúdo durante a disciplina de Empreendedorismo.

Quanto à identificação e avaliação de oportunidades, os resultados mostram que para atingir esse objetivo os docentes adotaram as técnicas didático-pedagógicas que envolvem aulas e palestras teóricas, artigos teóricos e avaliação de conteúdo. 


\section{O ESTUDO DA DISCIPLINA DE EMPREENDEDORISMO NAS INSTITUIÇÕES DE ENSINO SUPERIOR \\ DE ADMINISTRAÇÃO DE ARACAJU E DE SÃO CRISTÓVÃO (SE) \\ DOI: http://dx.doi.org/10.5007/1983-4535.2019v12n2p72}

Com relação à identificação de recursos necessários e o desenvolvimento de energia: motivação e perseverança, os docentes afirmaram priorizar as técnicas pedagógicas envolvendo palestras teóricas e avaliação de conteúdo, onde todas as IES confirmaram que também adotam as aulas teóricas para atingir esse objetivo.

De acordo com os resultados encontrados para os quesitos entender sobre gestão e desenvolver visão, é possível verificar que as Faculdades utilizam mais as práticas didáticopedagógicas aulas teóricas, leituras obrigatórias e avaliação de conteúdo.

Com esses resultados para as técnicas do $1^{\circ}$ (primeiro) quadrante da Matriz de Estilos de Aprendizagem e Técnicas Pedagógicas de Ulrich e Cole (1987), é possível concluir que as IES ainda priorizam práticas do modelo de educação tradicional como as aulas e palestras teóricas e, a avaliação de conteúdo.

No quadro 08 é possível visualizar o estilo e técnicas do quadrante II da Matriz de Ulrich e Cole (1987) aplicadas às IES.

Quadro 08 Estilo e Técnicas do quadrante II utilizadas pelas IES no desenvolvimento do perfil empreendedor

\begin{tabular}{|c|c|c|c|c|c|c|c|}
\hline $\begin{array}{l}\text { Estilo e Técnicas II } \\
\text { reflexivo-aplicado } \\
\text { (mudança na avaliação) }\end{array}$ & 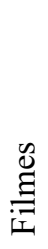 & 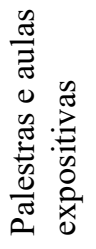 & $\begin{array}{l}n \\
0 \\
00 \\
0 \\
\frac{0}{0 \pi} \\
0\end{array}$ & 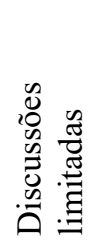 & $\begin{array}{l}0 \\
0 \\
0 \\
0 \\
0 \\
0 \\
0 \\
0 \\
0 \\
D \\
0 \\
\text { I }\end{array}$ & 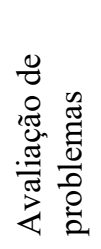 & 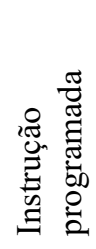 \\
\hline 1. Conhecer mudanças tecnológicas & 5 & 6 & 7 & 2 & 6 & 4 & 2 \\
\hline 2. Conhecer processos de inovação & 3 & 6 & 3 & 1 & 4 & 5 & 2 \\
\hline 3. Identificar/avaliar oportunidades & 5 & 5 & 5 & 3 & 5 & 2 & 2 \\
\hline 4. Desenvolver plano de negócios & - & 6 & 5 & 4 & 8 & 6 & 7 \\
\hline 5. Identificar recursos necessários & 1 & 6 & 6 & 1 & 4 & 2 & 1 \\
\hline 6. Entender sobre gestão & 5 & 6 & 4 & 2 & 5 & 4 & 3 \\
\hline 7. Desenvolver visão & 4 & 4 & 5 & 1 & 6 & 1 & 5 \\
\hline 8. Persuadir terceiros & 5 & 5 & 4 & 2 & 5 & 3 & 3 \\
\hline $\begin{array}{l}\text { 9. Desenvolver energia (motivação, } \\
\text { perseverança) }\end{array}$ & 4 & 5 & 4 & 3 & 5 & 2 & 4 \\
\hline 10. Aceitar riscos & 3 & 4 & 2 & 3 & 5 & 5 & 4 \\
\hline
\end{tabular}

Fonte: Pesquisa de campo (2016).

Quanto ao quadrante II, para o conhecimento de mudanças tecnológicas e identificação de recursos necessários, os docentes utilizam as técnicas didático-pedagógicas que abrangem diálogos, palestras e aulas expositivas e estudos de caso.

Com relação ao conhecimento dos processos de inovação, desenvolvimento de plano de negócios e aceitação de risco nas disciplinas de Empreendedorismo, as IES 


\section{O ESTUDO DA DISCIPLINA DE EMPREENDEDORISMO NAS INSTITUIÇÕES DE ENSINO SUPERIOR \\ DE ADMINISTRAÇÃO DE ARACAJU E DE SÃO CRISTÓVÃO (SE) \\ DOI: http://dx.doi.org/10.5007/1983-4535.2019v12n2p72}

entrevistadas afirmaram utilizar avaliação de problemas e estudos de caso como principais técnicas pedagógicas.

Para identificar e avaliar oportunidades, entender sobre gestão e persuadir terceiros, os professores do curso de Administração informaram adotar as práticas de ensino que abrangem filmes, palestras e aulas expositivas e estudos de caso.

No quesito desenvolver visão, os estudos de caso, os diálogos e a instrução programada foram os métodos de ensino mais citados pelos docentes da disciplina para atingir esse objetivo.

Para o desenvolvimento de energia: motivação e perseverança, as práticas didáticopedagógicas mais adotadas no ensino do Empreendedorismo são as palestras e aulas expositivas, os estudos de caso, os filmes, os diálogos e a instrução programada.

Então, pode-se afirmar que as palestras e aulas continuam sendo as práticas pedagógicas mais utilizadas nas IES para o ensino do Empreendedorismo, porém, neste quadrante de Ulrich e Cole (1987) o estilo reflexivo-aplicado é voltado à prática, e as aulas e palestras adotadas são expositivas, além da inclusão dos diálogos e dos estudos de caso durante as aulas da disciplina no curso de Administração.

Em relação às técnicas do quadrante III de Ulrich e Cole (1987), o Quadro 09 mostra as respostas das IES relacionadas ao estilo e às técnicas ativo-aplicada, da Matriz de Estilos de Aprendizagem e Técnicas Pedagógicas.

Quadro 09 Estilo e Técnicas do quadrante III utilizadas pelas IES no desenvolvimento do perfil empreendedor

\begin{tabular}{|c|c|c|c|c|c|c|}
\hline $\begin{array}{c}\text { Estilo e Técnicas III } \\
\text { ativo-aplicado } \\
\text { (mudanças em habilidades e atitudes) }\end{array}$ & $\begin{array}{l}0 \\
0 \\
0 \\
\stackrel{0}{0}\end{array}$ & 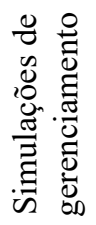 & 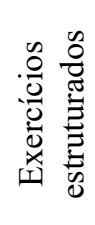 & 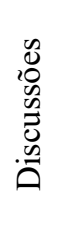 & 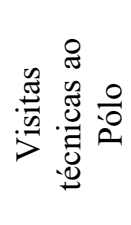 & 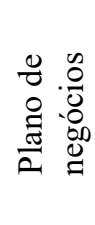 \\
\hline 1. Conhecer mudanças tecnológicas & 1 & 4 & 6 & 4 & 2 & 6 \\
\hline 2. Conhecer processos de inovação & 2 & 3 & 4 & 3 & 5 & 3 \\
\hline 3. Identificar/ avaliar oportunidades & 2 & 5 & 4 & 5 & 2 & 6 \\
\hline 4. Desenvolver plano de negócios & 3 & 6 & 6 & 4 & 2 & 7 \\
\hline 5. Identificar recursos necessários & - & 2 & 6 & 5 & - & 4 \\
\hline 6. Entender sobre gestão & 2 & 4 & 4 & 5 & 1 & 4 \\
\hline 7. Desenvolver visão & 1 & 4 & 3 & 6 & - & 7 \\
\hline 8. Persuadir terceiros & 2 & 5 & 2 & 3 & - & 2 \\
\hline $\begin{array}{l}\text { 9. Desenvolver energia (motivação, } \\
\text { perseverança) }\end{array}$ & 1 & 3 & 3 & 6 & 1 & 3 \\
\hline 10. Aceitar riscos & 3 & 4 & 1 & 3 & - & 2 \\
\hline
\end{tabular}

Fonte: Pesquisa de campo (2016). 


\section{O ESTUDO DA DISCIPLINA DE EMPREENDEDORISMO NAS INSTITUIÇÕES DE ENSINO SUPERIOR \\ DE ADMINISTRAÇÃO DE ARACAJU E DE SÃO CRISTÓVÃO (SE) \\ DOI: http://dx.doi.org/10.5007/1983-4535.2019v12n2p72}

Conforme os resultados do quadrante III, as práticas didático-pedagógicas adotadas para que os discentes conheçam as mudanças tecnológicas, desenvolvam planos de negócios, identificam e avaliam oportunidades, entendam sobre gestão e desenvolvam energia: motivação e perseverança e identificam recursos necessários são, principalmente, os exercícios estruturados, o plano de negócios, as simulações de gerenciamento e as discussões.

Para conhecer os processos de inovação são adotadas as visitas técnicas ao Pólo e os exercícios estruturados como principais técnicas de ensino do Empreendedorismo.

No quesito desenvolver visão, os graduandos em Administração, são motivados a desenvolver essa habilidade na disciplina de Empreendedorismo, através do plano de negócios, de discussões e de simulações de gerenciamento.

Para persuadir terceiros, simulações de gerenciamento e discussões são as principais técnicas pedagógicas adotadas pelos docentes durante o ensino do Empreendedorismo nas IES de Administração.

No que se refere à aceitação de riscos, os professores afirmam adotar, principalmente, as simulações de gerenciamento, os jogos e as discussões como técnicas pedagógicas que auxiliam no desenvolvimento do perfil empreendedor no graduando.

O Quadro 10 apresenta o estilo e as técnicas do IV quadrante da Matriz de Aprendizagem de Ulrich e Cole (1987).

Quadro 10 Estilo e Técnicas do quadrante IV utilizadas pelas IES no desenvolvimento do perfil empreendedor

\begin{tabular}{|c|c|c|c|c|c|c|c|}
\hline $\begin{array}{l}\text { Estilos de Aprendizagem e Técnica IV } \\
\text { ativo-teórico } \\
\text { (mudanças na compreensão, entendimento) }\end{array}$ & 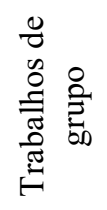 & $\frac{\mathscr{a}}{3}$ & 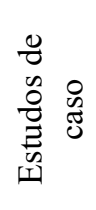 & 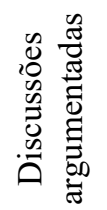 & 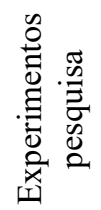 & 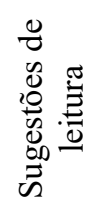 & 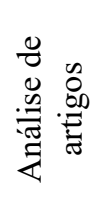 \\
\hline 1. Conhecer mudanças tecnológicas & 6 & 8 & 5 & 3 & 3 & 3 & 1 \\
\hline 2. Conhecer processos de inovação & 5 & 7 & 8 & 3 & 1 & 3 & 3 \\
\hline 3. Identificar/ avaliar oportunidades & 4 & 8 & 7 & 2 & 3 & - & - \\
\hline 4. Desenvolver plano de negócios & 6 & 7 & 5 & 5 & 2 & 4 & 3 \\
\hline 5. Identificar recursos necessários & 6 & 8 & 5 & 3 & 2 & 2 & 1 \\
\hline 6. Entender sobre gestão & 4 & 8 & 6 & 2 & 2 & 6 & 4 \\
\hline 7. Desenvolver visão & 4 & 5 & 4 & 3 & 1 & 2 & 3 \\
\hline 8. Persuadir terceiros & 5 & 5 & 5 & 2 & - & 2 & 2 \\
\hline $\begin{array}{l}\text { 9. Desenvolver energia (motivação, } \\
\text { perseverança) }\end{array}$ & 5 & 6 & 3 & 3 & 1 & 5 & 1 \\
\hline 10. Aceitar riscos & 3 & 5 & 2 & 5 & - & 4 & 1 \\
\hline
\end{tabular}

Fonte: Pesquisa de campo (2016). 
Com relação ao quadrante IV, as principais técnicas pedagógicas adotadas pelos docentes da disciplina de Empreendedorismo são as aulas, os trabalhos de grupo e os estudos de caso, para que os discentes conheçam mudanças tecnológicas, conheçam processos de inovação, identifiquem e avaliem oportunidades, identifiquem recursos necessários, desenvolvam visão e persuada terceiros.

No quesito desenvolver plano de negócios, os docentes selecionaram as aulas, os trabalhos de grupo, os estudos de caso e as discussões argumentadas como as principais práticas didático-pedagógicas que influenciam essa característica do desenvolvimento do perfil empreendedor no aluno.

Quanto a entender sobre gestão, as IES participantes da pesquisa optam, principalmente, pelas aulas, pelos estudos de caso e pelas sugestões de leitura nas aulas da disciplina de Empreendedorismo.

Tendo em vista o desenvolvimento de energia: motivação e perseverança, as aulas, os trabalhos de grupo e as sugestões de leitura são as técnicas de ensino mais utilizadas pelos docentes.

Para aceitar riscos, são adotadas as aulas, as discussões argumentadas e as sugestões de leitura para facilitar o aprendizado e incluir o aluno ativamente nas atividades da disciplina para que ele desenvolva e teste suas próprias teorias.

Tendo em vista que as técnicas pedagógicas dos quadrantes III e IV são as indicadas por Ulrich e Cole (1987) para efetivar o ensino e estimular a participação ativa dos alunos nas aulas, são essas técnicas de experimentação ativa que a maioria dos autores citados nesta pesquisa indica para que a disciplina de Empreendedorismo seja concluída não somente na teoria.

\section{CONCLUSÕES}

Esta pesquisa buscou analisar a influência das práticas didático-pedagógicas no estudo da disciplina de Empreendedorismo, adotadas pelas IES de Aracaju e de São Cristóvão.

A partir dos resultados da pesquisa, pode-se afirmar que, as Instituições de Ensino Superior ofertam a disciplina em períodos variados, a partir do $5^{\circ}$ período acadêmico em diante, porém em uma das IES participantes a disciplina é cursada no $1^{\circ}$ período onde os graduandos iniciantes ainda não possuem maturidade intelectual no curso para assimilar o conteúdo dessa disciplina. 


\section{O ESTUDO DA DISCIPLINA DE EMPREENDEDORISMO NAS INSTITUIÇÕES DE ENSINO SUPERIOR \\ DE ADMINISTRAÇÃO DE ARACAJU E DE SÃO CRISTÓVÃO (SE) \\ DOI: http://dx.doi.org/10.5007/1983-4535.2019v12n2p72}

Embora as disciplinas de Empreendedorismo ofertadas sejam lecionadas por professores com formação na área de Administração, parte delas aborda o tema apenas como item da ementa e não como tópico central, porém percebeu-se que, no Estado de Sergipe, as Instituições Acadêmicas estão adotando novas práticas didático-pedagógicas para estimular a aprendizagem e o desenvolvimento do perfil empreendedor durante o ensino do Empreendedorismo.

O objetivo das aulas teóricas, por ordem de prioridade, destacada pelos docentes da disciplina foram identificar recursos necessários, desenvolver plano de negócios, desenvolver visão, desenvolver energia: motivação e perseverança, conhecer mudanças tecnológicas, conhecer processos de inovação, identificar e avaliar oportunidades, entender sobre gestão, aceitar riscos, persuadir terceiros. Todas as Faculdades utilizam as práticas didáticopedagógicas desse Estilo de Aprendizagem.

No estilo reflexivo-aplicado, as práticas realizadas foram filmes, palestras e aulas expositivas, diálogos, discussões limitadas, estudos de casos, avaliação de problemas e instrução programa. Todas as Faculdades também utilizam todas essas práticas.

As práticas de jogos, simulações de gerenciamento, exercícios estruturados, discussões, visitas técnicas ao Pólo e plano de negócios foram questionadas no estilo ativoaplicado. E percebeu-se que todas as IES utilizam essas práticas de ensino.

Por fim, foi analisado o estilo ativo-teórico, que aborda as práticas de trabalho em grupo, aulas, estudos de caso, discussões argumentadas, experimentos ou pesquisa, sugestões de leituras e análise de artigos que foram citadas por todas as Instituições entrevistadas.

Cabe destacar que, além de utilizar as técnicas apresentadas na Matriz de Estilos de Aprendizagem e Técnicas Pedagógicas de Ulrich e Cole (1987), os docentes participantes das entrevistas citaram outras técnicas de ensino que fazem parte das aulas de Empreendedorismo, como entrevista ao empreendedor, visitas às empresas, pesquisa para compra de franquias, projeto de extensão em comunidade carente do bairro Santa Maria, projetos com o SEBRAE para oferta de cursos específicos e; apresentação no final do semestre, de produtos ou serviços criados pelos graduandos durante a disciplina.

Em relação às outras disciplinas que abordam o tema Empreendedorismo, apenas 5 (cinco) docentes afirmaram que as disciplinas Gestão de Projetos, Marketing, Gestão de Negócios, Planejamento Estratégico, Teoria da Organização, Formação de Consultores, Fundamentos de Gestão, Criatividade e Inovação, Administração de Serviços, Gestão 
Estratégica, Gestão de Pessoas, Consultoria Empresarial e, Teoria Geral da Administração II também tratam desse assunto na Instituição em que lecionam.

No que tange os assuntos acrescentados à ementa de Empreendedorismo, além dos sugeridos pelo Ministério da Educação (MEC), estão Propriedade Intelectual, Empreendedorismo Social, Franquias, Balanced Score Card (BSC) e, Desenvolvimento Local, que fazem parte do programa da disciplina em 4 (quatro) Faculdades.

Vale acrescentar que em 7 (sete) IES há abertura para opinião dos alunos quanto à inclusão de assuntos relevantes que não estão incluídos no programa da disciplina na graduação em Administração.

Considerando que a maioria das IES não acompanha o desenvolvimento profissional empreendedor do aluno egresso, 1 (uma) delas afirmou que, através de cadastro da própria Universidade, $10 \%$ (dez por cento) dos alunos que já cursaram a disciplina de Empreendedorismo se tornaram empreendedores.

\section{REFERÊNCIAS}

AMORÓS, J. E.; FERNÁNDEZ, C.; TAPIA, J. Empreendedorismo: uma investigação na evolução da perspectiva empreendedora dos estudantes de uma IES privada no Rio Grande do Norte. Revista Eletrônica de Estratégia \& Negócios, v. 5, n. 1, p. 28-66, $2012 .$.

ARAÚJO, R. M.; OLIVEIRA, F. P.; CHRISTO, R. S.; SILVA, D. O. Empreendedorismo: uma investigação na evolução da perspectiva empreendedora dos estudantes de uma IES privada no Rio Grande do Norte. Revista Eletrônica de Estratégia \& Negócios, v. 5, n. 1, p. 28-66, 2012.

BARDIN, L. Análise de Conteúdo. São Paulo: Edições 70, 2011.

BOAVENTURA, Maria Goreti; LOPES MELO, Marlene Catarina Oliveira. Criação de empresas por microempreendedores. Revista de Administração FACES Journal, v. 11, n. $2,2012$.

DORNELAS, J. C. A. Empreendedorismo: transformando ideias em negócios. Rio de Janeiro: Elsevier, 2008.

DRUCKER, Peter Ferdinand. Inovação e espírito empreendedor (entrepreneurship): prática e princípios. Tradução de Carlos Malferrari. São Paulo: Pioneira, v. 4, 1987.

ESTÁCIO FASE - Faculdade Estácio de Sergipe.

Administração - Bacharelado. 2016.Disponível em:

$<$ http://portal.estacio.br/graduacao/administra\%C3\%A7\%C3\%A3o-bacharelado $>$. Acesso em: 30 de março de 2016. 
FAMA - Faculdade Amadeus. Graduação em Administração. 2016. Disponível em: $<$ http://www.faculdadeamadeus.com.br/Graduacao/Web/content/graduacao/administracao/ind ex.html>. Acesso em: 05 de junho de 2016.

FANESE - Faculdade de Administração e Negócios de Sergipe. Bacharelado em Administração. 2016. Disponível em: $<$ http://portal.fanese.edu.br/?page_id=188>. Acesso em: 05 de junho de 2016.

FASER - Faculdade Sergipana. Administração - Curso Superior de Graduação Tradicional. 2016. Disponível em: $<$ http://www.faserse.edu.br/ensino/graduacao/tradicionais/administracao.asp>. Acesso em: 03 de junho de 2016.

FASERGY - Faculdade Serigy. Curso de Administração. 2016. Disponível em: $<$ http://www.serigy.net.br/index.php?option $=$ com_content\&view $=$ category\&layout=blog\&id $=39 \&$ Itemid $=65>$. Acesso em: 02 de junho de 2016 .

FILION, Louis Jacques. Empreendedorismo: empreendedores e proprietários-gerentes de pequenos negócios. Revista de administração, v. 34, n. 2, p. 5-28, 1999.

FSLF - Faculdade São Luís de França. Apresentação - Administração. 2016. Disponível em:

$<$ http://www.faculdadesaoluisdefranca.com.br/index.php?option=com_content\&view=article \&id=45\&Itemid=55> . Acesso em: 29 de maio de 2016.

GARCIA, R.; ARAÚJO, V.; MASCARINI, S., Silva, A. O.; ASCÚA, R. Empreendedorismo acadêmico no Brasil: uma avaliação da propensão à criação de empresas por estudantes universitários. REGEPE-Revista de Empreendedorismo e Gestão de Pequenas Empresas, v. 1, n. 3, p. 36-63, 2012.

GIL, A. C. Como elaborar projetos de pesquisa. 5a ed. São Paulo: Atlas, 2010.

HISRICH, R. D.; PETERS, M. P.; SHEPHERD, D. A. Empreendedorismo. $7^{\text {a }}$ ed. Porto Alegre: AMGH, 2014.

IBQP - INSTITUTO BRASILEIRO DA QUALIDADE E PRODUTIVIDADE. Empreendedorismo no Brasil: relatório executivo. Curitiba: IBQP, 2012.

. Empreendedorismo no Brasil: relatório executivo. Curitiba: IBQP, 2013.

MARTINELLI, Luís Alberto Saavedra; FLEMING, Evelyn Strauss. O comportamento empreendedor: a influência das características emocionais na motivação dos indivíduos para a ação empreendedora. Anais do Encontro da Associação Nacional de Pós-Graduação e Pesquisa em Administração, Rio de Janeiro, RJ, Brasil, v. 34, 2010.

MASSAINI, Silvye Ane et al. Empreendedorismo e competitividade global: uma análise multivariada de dados. Revista Gestão Organizacional, v. 5, n. 2, p. 259, 2012.

SCHUMPETER, J. A. The Theory of Economic Development. Cambridge, Ma: Harvard University Press, 1934. 
Capitalism, Socialism and Democracy. New York: Harper and Row, 1950.

. Teoria do desenvolvimento econômico: uma investigação sobre lucros, capital, crédito, juro e o ciclo econômico. São Paulo: Abril Cultural, 1982.

SOARES, M. A. F.; MACHADO, H. P. V. Jovens empreendedores: perfil, dificuldades na gestão e perspectivas dos empreendimentos. V Encontro de Estudos sobre Empreendedorismo e Gestão de Pequenas Empresas (EGEPE), Anais..., Curitiba, 2005.

UFS - Universidade Federal de Sergipe. Administração/DAD - São Cristóvão. 2016. Disponível em:

$<$ https://www.sigaa.ufs.br/sigaa/public/curso/portal.jsf?lc=pt_BR\&id=320123 $>$. Acesso em: 28 de maio de 2016.

ULRICH, Thomas A.; COLE, George S. Toward more effective training of future entrepreneurs. Journal of Small Business Management, v. 25, n. 4, p. 32, 1987. UNINASSAU - Faculdade Maurício de Nassau de Aracaju. Informação do curso: Administração. 2016. Disponível em:

$<$ https://vestibular.uninassau.edu.br/curso/3/3/4/administracao/Aracaju-SE $>$. Acesso em: 30 de maio de 2016.

UNIT - Universidade Tiradentes. Administração - Informações. 2016. Disponível em: $<$ http://www.unit.br/cursos/cursos-graduacao/administracao/>. Acesso em: 25 de maio de 2016.

Vieira, S. F. A.; Melatti, G. A.; Oguido, W. S.; Pelisson, C.; Negreiros, L. F. Ensino de empreendedorismo em cursos de Administração: um levantamento da realidade brasileira. Revista de Administração FACES Journal Belo Horizonte, v.12, n.2, p.93-114, 2013.

YIN, Robert K. Estudo de caso: Planejamento e Métodos. $4^{\text {a }}$ ed. Porto Alegre: Bookman, 2010.

YSHIKAWA SALUSSE, Marcus Alexandre; ANDREASSI, Tales. O Ensino de Empreendedorismo com Fundamento na Teoria Effectuation. RAC-Revista de Administração Contemporânea, v. 20, n. $3,2016$. 